Article

\title{
The Gas-Phase Formation Mechanism of Dibenzofuran (DBF), Dibenzothiophene (DBT), and Carbazole (CA) from Benzofuran (BF), Benzothiophene (BT), and Indole (IN) with Cyclopentadienyl Radical
}

\author{
Xuan Li ${ }^{1,+}$, Yixiang Gao ${ }^{1,+}$, Chenpeng Zuo ${ }^{1,2}$, Siyuan Zheng ${ }^{1}$, Fei Xu ${ }^{1,2, *}$, Yanhui Sun ${ }^{3}$ and \\ Qingzhu Zhang ${ }^{1}$ \\ 1 Environment Research Institute, Shandong University, Qingdao 266237, China; \\ 1x18265450270@126.com (X.L.); yixianggao@163.com (Y.G.); zuochenpeng@126.com (C.Z.); \\ zhengsiyuan1991@126.com (S.Z.); zqz@sdu.edu.cn (Q.Z.) \\ 2 Shenzhen Research Institute, Shandong University, Shenzhen 518057, China \\ 3 College of Environment and Safety Engineering, Qingdao University of Science \& Technology, \\ Qingdao 266042, China; sunyh0532@126.com \\ * Correspondence: xufei@sdu.edu.cn; Tel.: +86-532-58631992 \\ + These authors contributed equally to this article.
}

Received: 11 August 2019; Accepted: 28 October 2019; Published: 31 October 2019

\begin{abstract}
Benzofuran (BF), benzothiophene (BT), indole (IN), dibenzofuran (DBF), dibenzothiophene (DBT), and carbazole (CA) are typical heterocyclic aromatic compounds (NSO-HETs), which can coexist with polycyclic aromatic hydrocarbons (PAHs) in combustion and pyrolysis conditions. In this work, quantum chemical calculations were carried out to investigate the formation of DBF, DBT, and $\mathrm{CA}$ from the reactions of $\mathrm{BF}, \mathrm{BT}$, and IN with a cyclopentadienyl radical (CPDyl) by using the hybrid density functional theory (DFT) at the MPWB1K/6-311+G(3df,2p)//MPWB1K/6-31+G(d,p) level. The rate constants of crucial elementary steps were deduced over 600-1200 K, using canonical variational transition state theory with a small-curvature tunneling contribution (CVT/SCT). This paper showed that the production of DBF, DBT, and CA from the reactions of $\mathrm{BF}, \mathrm{BT}$, and IN with CPDyl involved six elementary steps: the addition reaction, ring closure, the first $\mathrm{H}$ shift, $\mathrm{C}-\mathrm{C}$ cleavage, the second $\mathrm{H}$ shift, and elimination of $\mathrm{CH}_{3}$ or $\mathrm{H}$. The cleavage of the $\mathrm{C}-\mathrm{C}$ bond was regarded as the rate-determining step for each pathway due to the extremely high barrier. The 1-methyl substituted products were more easily formed than the 4-methyl substituted products. The main products were DBF and 1-methyl-DBF, DBT and 1-methyl-DBT, and CA and 1-methyl-CA for reactions of $\mathrm{BF}, \mathrm{BT}$, and IN with $\mathrm{CPDyl}$, respectively. The ranking of $\mathrm{DBF}, \mathrm{DBT}$, and CA formation potential was as follows: DBT and methyl-DBT formation $>$ DBF and methyl-DBF formation > CA, and methyl-CA formation. Comparison with the reaction of naphthalene with CPDyl indicated that the reactions of CPDyl attacking a benzene ring and a furan/thiophene/pyrrole ring could be inferred to be comparable under high temperature conditions.
\end{abstract}

Keywords: nso-hets; formation mechanism; cyclopentadienyl; rate constant; density functional method

\section{Introduction}

Polycyclic aromatic compounds (PACs), including polycyclic aromatic hydrocarbons (PAHs) and heterocyclic aromatic compounds (NSO-HETs), have become a considerable threat to the environment and human health because of their acute toxicity, mutagenicity, photoinduced toxicity, and carcinogenic 
potential $[1,2]$. The emissions of PAHs are often associated with releases of NSO-HETs, which have been reported to comprise up to $10 \%$ and $40 \%$ of the total PAH emissions in tar-oil or coal tar and its water-soluble fraction, respectively [3-6].

Benzofuran (BF), benzothiophene (BT), indole (IN), dibenzofuran (DBF), dibenzothiophene (DBT), and carbazole (CA) are typical NSO-HETs, which are composed of a benzene ring and a furan/thiophene/pyrrole ring. Furan/thiophene/pyrrole rings are five-membered ring in which the heteroatoms have at least one pair of non-binding valence shell electrons. BF, BT, and IN (benzo-NSO-HETs) include one benzene ring and one heterocyclic five-membered ring; DBF, DBT, and CA (dibenzo-NSO-HETs) consist of two benzene rings fused together on either side of a furan/thiophene/pyrrole ring, respectively. They have been found to be toxic and mutagenic [7]. DBF has been used as an insecticide, a component in heat-transfer oils, and a carrier for dyeing and printing textiles [8,9]. DBT is an important intermediate in the production of cosmetics and pharmaceuticals, and a model compound in the hydrodesulfurization reaction for diesel oil. CA has been widely used in insecticides, explosives, dyes, reagents, lubricants, and detergents [10-12], and in the pharmaceutical industry to treat encephalopathy, cardiopathy, hepatopathy, and arteriosclerosis $[10,13]$. Dibenzo-NSO-HETs are widely found in creosote, coal tar, and crude oils, as well as in some high temperature processes of waste incineration, tobacco smoke, aluminum manufacturing, forest fire, rubber, petroleum, fossil fuel, and coal and wood combustion [7,14-18], and always coexist with other aromatic compounds, such as PAHs and benzo-NSO-HETs [15,19-25]. Wikstrom reported that a high concentration of DBF was measured in artificial municipal solid waste fuel, and that the concentration of DBF $\left(19,800 \mathrm{ng} / \mathrm{nm}^{3}\right)$ was 100-1000 times and 10-100 times higher than that of PCDFs before and after the convector section, respectively [26]. DBF (190-210 ng/g), DBT (190 ng/g), and CA (1.5-1.6 ng/g) were detected by Ishikawa in nine types of industrial wastes and their pyrolytic decomposition products [19]. Gu reported that the concentration of DBT was 50-100 times higher than that of DBT in coal pyrolysis, where the highest concentration was found at $500-600{ }^{\circ} \mathrm{C}$ [27]. Methyl-DBF, methyl-DBT, and methyl-CA can be widely detected along with DBF, DBT, and CA in sediment, ground water, oil fuel, and other thermal process [1,28-33]. For example, DBT and 18 alkyl homologs were detected in coastal sediments in Qatar, and the concentration of alkylated DBT was 10-50 times than that of DBT [29]. Three isomers of methyl-DBT (1-methyl-DBT, 2 or 3-metyl-DBT, and 4-methyl-DBT), were identified by Rebbert in crude oil, in which 4-methyl-DBT was the obtained with the highest precision at a concentration of $33.9 \mu \mathrm{g} / \mathrm{g}$ [28].

Recently, several studies have revealed a considerably stronger relationship of dibenzo-NSO-HET and benzo-NSO-HET mass concentrations or isomer distributions in thermal processes. For example, Dartiguelongue found that DBT thermal cracking led to the formation of BT, phenyl-DBT, and other sulfur-containing molecules under isothermal pyrolysis conditions $\left(375-500{ }^{\circ} \mathrm{C}\right)$ [27]. Sobkowiak reported a linear correlation between fuel phenol concentration with IN and CA in fuel-improved thermal oxidation under $1000{ }^{\circ} \mathrm{C}$ [21]. The formation enthalpies of 4-methylbenzofuran + naphthalene $\rightarrow$ dibenzofuran + toluene and 4-methylbenzofuran + anthracene $\rightarrow$ dibenzofuran +1 -methylnaphthalene were calculated at G3(MP2)//B3LYP to be -22.5 and $-21.1 \mathrm{Kj} / \mathrm{mol}$ by Freitas at the fusion and combustion temperatures, respectively [22]. The cyclopentadienyl radical $\left(\mathrm{C}_{5} \mathrm{H}_{5}, \mathrm{CPDyl}\right)$ is among the most abundant radicals formed during the combustion and pyrolysis of many hydrocarbons [34-38]. Winkler studied the gas-phase pyrolysis of heterocyclic compounds in the flow pyrolysis and annulation reactions of some sulfur heterocycles, and found that DBF was produced from the reaction of BF with $\mathrm{C}_{4} \mathrm{H}_{2}$ above $850{ }^{\circ} \mathrm{C}$ [22]. Xing focused on the release behavior of thiophenic sulfur compounds during coal pyrolysis, and obtained levels of benzothiophene and dibenzothiophene during pyrolysis at temperatures ranging from $200{ }^{\circ} \mathrm{C}$ to $1300{ }^{\circ} \mathrm{C}$, with the peak values reached at $800{ }^{\circ} \mathrm{C}$. The amount of benzothiophene and dibenzothiophene released was much higher at a rapid pyrolysis rate than at a medium heating rate [22].

The CPDyl radical can be produced in high-temperature conditions by pyrolysis or unimolecular decomposition reactions of cyclopentadiene $\left(\mathrm{C}_{5} \mathrm{H}_{6}\right) \rightarrow \mathrm{C}_{5} \mathrm{H}_{5}+\mathrm{H}$, phenoxy radical $\left(\mathrm{C}_{6} \mathrm{H}_{5} \mathrm{O}\right) \rightarrow \mathrm{C}_{5} \mathrm{H}_{5}+$ 
$\mathrm{CO}$ and acetylene $\left(\mathrm{C}_{2} \mathrm{H}_{2}\right)+$ propargyl radical $\left(\mathrm{C}_{3} \mathrm{H}_{3}\right) \rightarrow \mathrm{C}_{5} \mathrm{H}_{5}$. The experimental rate constants of $\mathrm{C}_{5} \mathrm{H}_{6}$ $\rightarrow \mathrm{C}_{5} \mathrm{H}_{5}+\mathrm{H}$ and $\mathrm{C}_{6} \mathrm{H}_{5} \mathrm{O} \rightarrow \mathrm{C}_{5} \mathrm{H}_{5}+\mathrm{CO}$ are $2.3 \times 10^{1} \mathrm{~s}^{-1}$ and $2.5 \times 10^{3} \mathrm{~s}^{-1}$, respectively [19,34-36,39-44]. Among many potential precursors for aromatic growth, $\mathrm{CPDyl}$ is considered to be important in the formation and growth of PAHs, because it is neutral, ambidentally reactive at different sites, and has the ability of self-recombination [19,34-36,39-44]. Our recent studies proposed a detailed PAH growth mechanism from the reaction of naphthalene with CPDyl, followed by conversion of five-membered rings to six-membered rings, and found that the formation potential of bend products was larger than that of linear products [45]. Considering the structure and property similarities of dibenzo-NSO-HETs and benzo-NSO-HETs, and the coexistence of dibenzo-NSO-HETs and benzo-NSO-HETs with PAHs, the formation pathways of dibenzo-NSO-HETs from benzo-NSO-HETs with CPDyl were inferred to be similar to the growth mechanisms of PAH with CPDyl, where the five-membered ring of CPDyl can convert to a benzene ring followed by the addition reaction to benzo-NSO-HETs. As far as we know, there is no information available on dibenzo-NSO-HET formation mechanisms from benzo-NSO-HETs with the CPDyl radical.

Due to the high toxicity of dibenzo-NSO-HETs and the lack of efficient detection methods for intermediate radicals, the detailed formation mechanism of dibenzo-NSO-HETs from benzo-NSO-HETs with CPDyl has not been completely elucidated. Quantum chemical calculations can be widely used to predict favorable reaction pathways and elucidate the yield of the products, and theoretical modeling allows direct contact with the highly toxic compounds to be avoided. In this study, we present an overall density functional theory (DFT) study of dibenzofuran (DBF), dibenzothiophene (DBT), and carbazole (CA) formation mechanisms from the reactions of benzofuran (BF), benzothiophene (BT), and indole (IN) with CPDyl, respectively. All possible formation pathways involved in dibenzo-NSO-HET formation from benzo-NSO-HETs with the CPDyl radical were studied. Some energetically preferred routes were proposed to parallel the formation possibility of different dibenzo-NSO-HET products and explain experimental observations. Secondly, rate constants for the elementary reactions were evaluated over a wide temperature range of $600-1200 \mathrm{~K}$. The absence of the kinetic parameters prevent further improvement and optimization of the NSO-HETs formation models. The third aim was to compare the effect of the $\mathrm{O}, \mathrm{S}$, and $\mathrm{N}$ atom substitution pattern of benzo-NSO-HETs on the isomer patterns and formation potential of dibenzo-NSO-HETs.

\section{Results}

For convenience of interpretation, the $\mathrm{C}$ atoms of benzofuran (BF), benzothiophene (BT), indole (IN), dibenzofuran (DBF), dibenzothiophene (DBT), and carbazole (CA) were labeled, as presented in Figure 1.

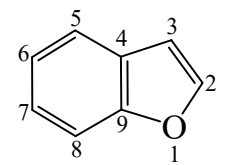

benzofuran(BF)

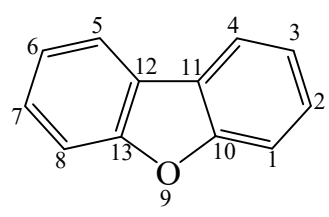

dibenzofuran(DBF)<smiles>c1ccc2sccc2c1</smiles>

benzothiophene(BT)

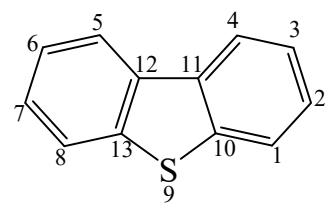

dibenzothiophene(DBT)

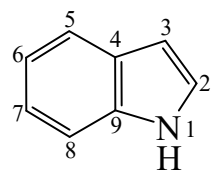

indole(IN)

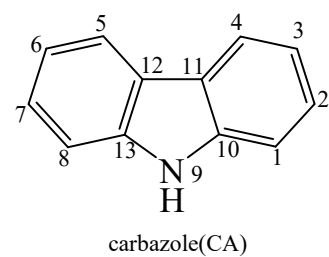

Figure 1. The structures of benzofuran (BF), benzothiophene (BT), indole (IN), dibenzofuran (DBF), dibenzothiophene (DBT), and carbazole (CA) with labeled $\mathrm{C}$ atoms. 
It is crucial to clarify the reliability and accuracy of the theoretical calculations. The geometric parameters and the vibrational frequencies of BF, BT, IN, DBF, DBT, and CA were calculated at the MPWB95/6-31+G(d,p) level and compared with the experimental values in Tables S3-S5 of Supporting Information. The results at the MPWB95/6-31+G(d,p) level were in accordance with the experimental data, and the average relative error remained within 3.3\% for the geometrical parameters [46-50], and less than $5.7 \%$ for the vibrational frequencies of BF, BT, IN, DBF, DBT, and CA [51-54]. To verify the reliability of the energies, we calculated the reaction heats for benzofuran $\left(\mathrm{C}_{8} \mathrm{H}_{6} \mathrm{O}\right)+$ cyclopentadiene $\left(\mathrm{C}_{5} \mathrm{H}_{6}\right) \rightarrow$ dibenzofuran $\left(\mathrm{C}_{12} \mathrm{H}_{8} \mathrm{O}\right)+\mathrm{CH}_{4}$, benzothiophene $\left(\mathrm{C}_{8} \mathrm{H}_{6} \mathrm{~S}\right)+$ cyclopentadiene $\left(\mathrm{C}_{5} \mathrm{H}_{6}\right) \rightarrow$ dibenzothiophene $\left(\mathrm{C}_{12} \mathrm{H}_{8} \mathrm{~S}\right)+\mathrm{CH}_{4}$, and indole $\left(\mathrm{C}_{8} \mathrm{H}_{7} \mathrm{~N}\right)+$ cyclopentadiene $\left(\mathrm{C}_{5} \mathrm{H}_{6}\right) \rightarrow$ carbazole $\left(\mathrm{C}_{12} \mathrm{H}_{9} \mathrm{~N}\right)+\mathrm{CH}_{4}$ at the MPWB1K/6-311+G(3df,2p)//MPWB1K/6-31+G(d,p) level. The calculated values of $-41.5 \mathrm{kcal} / \mathrm{mol},-39.7 \mathrm{kcal} / \mathrm{mol}$, and $-40.1 \mathrm{kcal} / \mathrm{mol}$ at $298 \mathrm{~K}$ showed good consistency with the corresponding experimental values of $-43.0 \mathrm{kcal} / \mathrm{mol},-39.8 \mathrm{kcal} / \mathrm{mol}$, and $-38.3 \mathrm{kcal} / \mathrm{mol}$ obtained from the measured standard formation heats $\left(\Delta H_{\mathrm{f}, 0}\right)$ of BF, BT, IN, DBF, DBT, CA, and CPDyl [55-62]. From these results, we inferred that accuracy can be expected for the species in this study.

\subsection{Reaction of Benzofuran, Benzothiophene, and Indole with Cyclopentadienyl}

Figures 2-4 schematically illustrate the proposed reaction pathways for dibenzofuran (DBF), dibenzothiophene (DBT), and carbazole (CA) formation mechanisms from the reactions of benzofuran (BF), benzothiophene (BT), and indole (IN) with the cyclopentadienyl radical (CPDyl), respectively. The activation barriers $\Delta E$ (in $\mathrm{kcal} / \mathrm{mol}$ ) and reaction heats $\Delta H$ (in $\mathrm{kcal} / \mathrm{mol}$ ) were calculated at the MPWB1K/6-311+G(3df,2p)//MPWB1K/6-31+G(d,p) level. The activation barrier $\Delta E$ is the relative energy of the transition state with respect to the total energy of the separated reactants. The reaction heats $\Delta H$ is the relative energy of total energy of the products with respect to the total energy of reactants. Positive values of $\Delta H$ indicate endothermic reactions, and negative values indicate exothermic reactions. The relative activation barriers $\Delta E_{r}$ (in kcal $/ \mathrm{mol}$ ) and relative reaction heats $\Delta H_{r}$ (in $\mathrm{kcal} / \mathrm{mol}$ ) for all the elementary reactions in Figures $2-4$ at the MPWB1K/6-311+G(3df,2p)//MPWB1K/6-31+G(d,p) level are shown in Table $\mathrm{S} 2$ of the Supporting Information. The relative activation barrier $\Delta E_{r}$ is the relative energy of the transition state with respect to the total energy of the BF/BT/IN and CPDyl. The relative reaction heat $\Delta H_{r}$ is the relative energy of the total energy of the products with respect to the total energy of the BF/BT/IN and CPDyl. Four possible pathways (denoted as pathways 1-4 in Figure 2, pathways 5-8 in Figure 3, and pathways 9-12 in Figure 4) are postulated in each figure, resulting in three oxygen heterocycle dibenzo-NSO-HET congeners (DBF, 1-methyl-DBF, and 4-methyl-DBF) in Figure 2, three sulfur heterocycle dibenzo-NSO-HET congeners (DBT, 1-methyl-DBT, and 4-methyl-DBT) in Figure 3, and three nitrogen heterocycle dibenzo-NSO-HET congeners (CA, 1-methyl-CA, and 4-methyl-CA) in Figure 4.

The CPDyl radical has an unpaired electron, while the benzo-NSO-HET molecule has $\mathrm{C}=\mathrm{C}$ conjugated $\pi$ bonds. Thus, the reaction of benzo-NSO-HETs with the CPDyl radical can proceed through an addition reaction. The $\mathrm{C}$ atoms in benzo-NSO-HETs can be divided into three groups: $\mathrm{C} 2$ and $\mathrm{C} 3$ belong to the five-membered ring; $\mathrm{C} 4$ and $\mathrm{C} 9$ are inside the "bend" of the benzo-NSO-HET molecules; C5, C6, C7, and C8 belong to the six-membered benzene ring. Among them, CPDyl additions to $\mathrm{C} 4$ and $\mathrm{C} 9$ are sterically hindered, and additions to $\mathrm{C} 5, \mathrm{C} 6, \mathrm{C} 7$, and $\mathrm{C} 8$ could not form the dioxin-like dibenzo-NSO-HETs. Our previous work studied the formation and growth mechanism of PAHs from the reactions of naphthalene with CPDyl, and found that the potential barriers of the CPDyl addition to aromatic benzene ring are 16.3 and $18.4 \mathrm{kcal} / \mathrm{mol}$ : close to the $11.8-16.5 \mathrm{kcal} / \mathrm{mol}$ of the CPDyl addition to the five-membered furan/thiophene/pyrrole rings, except the energetically unfavored $20.5 \mathrm{kcal} / \mathrm{mol}$ of BF. This indicates that CPDyl addition to the six-membered ring (C5-C8) and five-membered ring (C2-C3) is energetically competitive. However, only CPDyl additions to $\mathrm{C} 2$ and $\mathrm{C} 3$ of benzo-NSO-HETs can form dibenzo-NSO-HET products. Thus, in this study, CPDyl additions to $\mathrm{C} 2$ and $\mathrm{C} 3$ of the furan ring of BF (resulting in IM1 and IM2), CPDyl additions to C2 and C 3 of the thiophene ring of BT (resulting in IM12 and IM13), and CPDyl additions to C2 and C3 
of the pyrrole ring of IN (resulting in IM23 and IM24) are discussed in detail in Figure 2, Figure 3, and Figure 4, respectively. In Figure 1, calculations show that the $\mathrm{C} 2$ and C 3 additions via TS1 and TS2 have high activation barriers of $15.8 \mathrm{kcal} / \mathrm{mol}$ and $20.5 \mathrm{kcal} / \mathrm{mol}$, respectively, indicating that CPDyl addition to $\mathrm{C} 2$ of $\mathrm{BF}$ is energetically preferred compared to addition to C3 of BF. Similarly, CPDyl addition to $\mathrm{C} 2$ of $\mathrm{BT}$ can occur via $15.9 \mathrm{kcal} / \mathrm{mol}$, which is lower than the addition to $\mathrm{C} 3$ of $\mathrm{BT}$. However, CPDyl addition to $\mathrm{C} 2$ of IN has a much higher activation barrier $(15.7 \mathrm{kcal} / \mathrm{mol})$ than CPDyl addition to $\mathrm{C} 3(11.8 \mathrm{kcal} / \mathrm{mol})$ of IN, which means that CPDyl addition to C3 can take place much more readily than to $\mathrm{C} 2$ in CA formation from IN with CPDyl. After the addition reactions, IM1/IM2, IM12/IM13, and IM23/IM24 undergo the ring close step to form the same intermediates, IM3, IM14, and IM25, respectively, which means that the first two steps of the different pathways in each figure are identical. The structures with the geometrical parameters of transition states and intermediates involved in this study are shown Figures S1-S3 of the Supporting Information, and the cartesian coordinates for transition states and intermediates are displayed in Tables S7 and S8 of the Supporting Information.

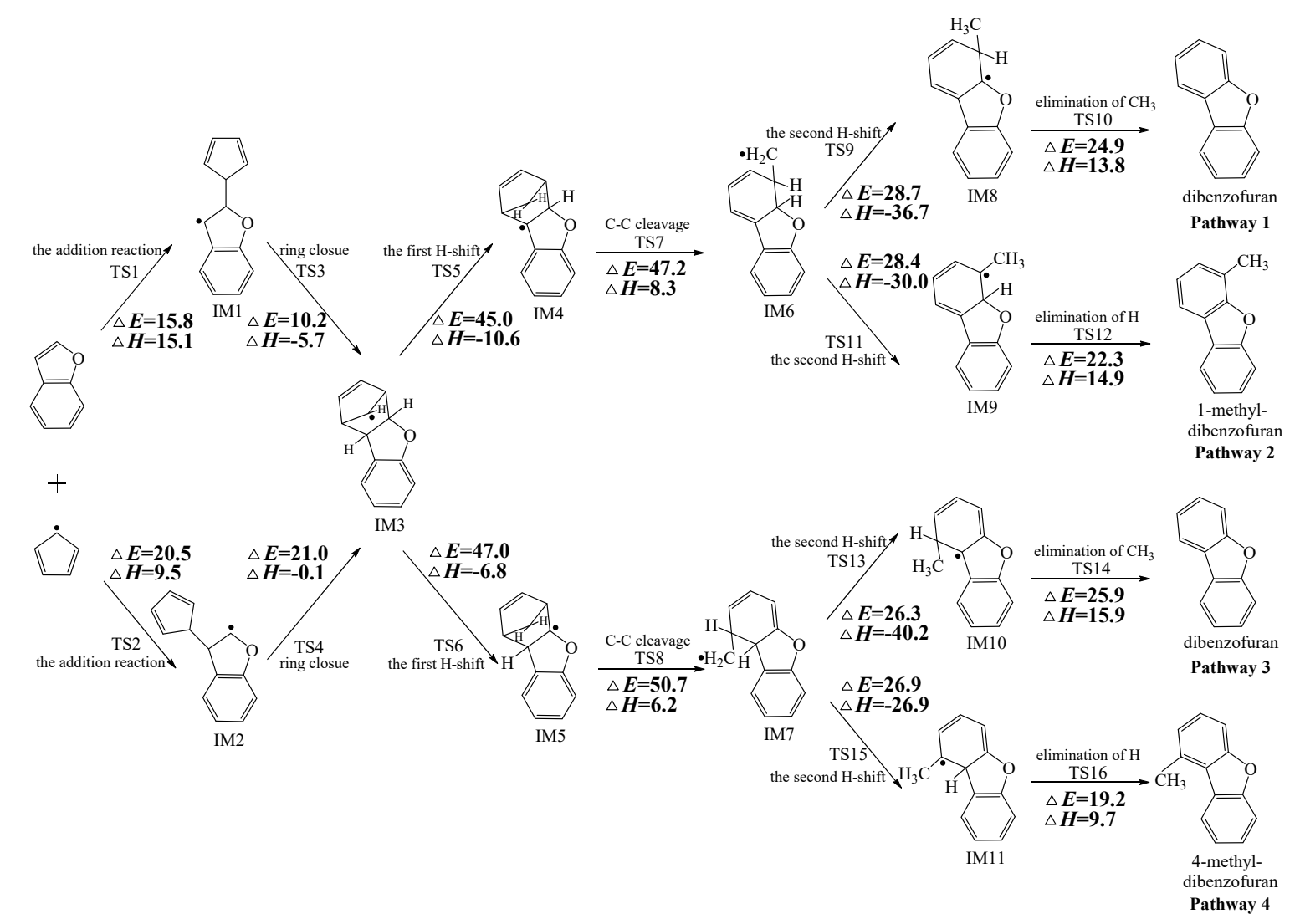

Figure 2. Dibenzofuran (DBF) formation routes presented with the activation barriers $\Delta E$ (in $\mathrm{kcal} / \mathrm{mol}$ ) and reaction heats $\Delta H$ (in $\mathrm{kcal} / \mathrm{mol}$ ) in the reaction of benzofuran $(\mathrm{BF})$ with cyclopentadienyl radical (CPDyl). $\Delta H$ has been calculated at $0 \mathrm{~K}$.

In Figures 2-4, each pathway is comprised of six elementary steps: (1) the addition reaction; (2) ring closure; (3) the first $\mathrm{H}$ shift; (4) C-C cleavage; (5) the second $\mathrm{H}$ shift, and (6) unimolecular elimination of $\mathrm{CH}_{3}$ or $\mathrm{H}$. All of the $\mathrm{H}$-shift steps are strongly exothermic, while the other steps are endothermic. The $\mathrm{C}-\mathrm{C}$ cleavage steps and the first $\mathrm{H}$-shift steps need to overcome high activation barriers exceeding $40 \mathrm{kcal} / \mathrm{mol}$. At high-temperature conditions in combustion and thermal processes, these activation barriers are easily overcome. For each pathway, the $\mathrm{C}-\mathrm{C}$ cleavages are the rate-determining steps owing to their high activation barriers $(47.2 \mathrm{kcal} / \mathrm{mol}$ and $50.7 \mathrm{kcal} / \mathrm{mol}$ in Figure $2,44.6 \mathrm{kcal} / \mathrm{mol}$ and $45.5 \mathrm{kcal} / \mathrm{mol}$ in Figure 3, and $46.5 \mathrm{kcal} / \mathrm{mol}$ and $47.8 \mathrm{kcal} / \mathrm{mol}$ in Figure 4). The structures, along with the geometrical parameters for the first/second H-shift transition states in the DBF formation routes 
from BF with CPDyl are shown in Figure 5. In Figures 2 and 5, pathways 1-2 can occur from via the same first $\mathrm{H}$-shift step, where the $\mathrm{H}$ atom bonded to the C-ortho bend $\mathrm{C}$ (C11) transfers to the bridge $\mathrm{C}$ of DF (the first $\mathrm{C} 11-\mathrm{H}$ shift); pathways 3-4 can occur via the same first $\mathrm{H}$-shift step, where the $\mathrm{H}$ atom bonded to the O-ortho bend C (C11) transfers to the bridge $\mathrm{C}$ of $\mathrm{DF}$ (the first $\mathrm{C} 10-\mathrm{H}$ shift). Similarly, pathways 5-6 in Figure 3 and pathways 9-10 in Figure 4 arise from the first C11-H shift, whereas pathways 7-8 in Figure 3 and pathways 11-12 in Figure 4 arise from the first C10-H shift. In Figure 2, pathways 1-2 can occur via the same intermediate IM6, and the distinctions of pathways 1-2 lie in the final two elementary steps, the second $\mathrm{H}$ shift and the elimination of $\mathrm{CH}_{3} / \mathrm{H}$. Similarly, pathways 3-4 have the same intermediate IM7, with the last two steps being difference. In pathways 1 and 3, the second $\mathrm{H}$-shift steps are identical, where the $\mathrm{H}$ atom bonded to the same carbon atom (with $-\mathrm{CH}_{2}$ ) transfers to $-\mathrm{CH}_{2}$ (the second same $\mathrm{C}-\mathrm{H}$ shift), resulting in the elimination of $\mathrm{CH}_{3}$ in the last step. Thus, the main products of pathways 1 and 3 are DBF without methyl substitution. However, in pathways 2 and 4, the second $\mathrm{H}$-shift steps were similar, where the $\mathrm{H}$ atom bonded to the ortho carbon atom (inside the bend) transfers to $-\mathrm{CH}_{2}$ (the second ortho $\mathrm{C}-\mathrm{H}$ shift), resulting in the elimination of $\mathrm{H}$ and retaining the methyl in the last step. Thus, the main products of pathway 2 and 4 are methyl-DBF, i.e., 1-methyl-DBF and 4-methyl-DBF. From Figure 5, the second $\mathrm{H}$ shift in pathways 1 and 3 can occur via a four-member ring transition state, while the second $\mathrm{H}$ shift in pathways 2 and 4 can occur via a three-member ring transition state.

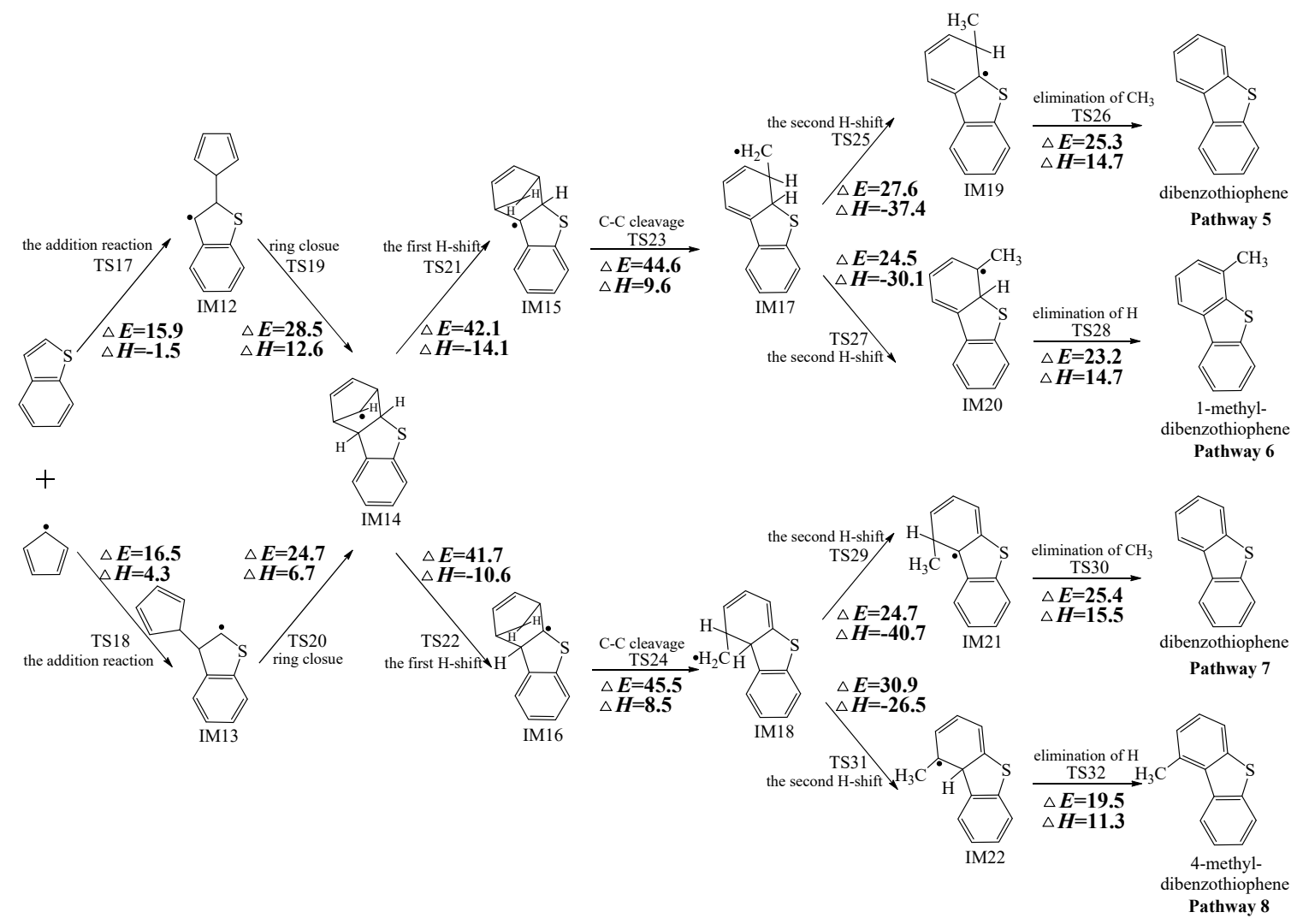

Figure 3. Dibenzothiophene (DBT) formation routes embedded with the activation barriers $\Delta E$ (in $\mathrm{kcal} / \mathrm{mol}$ ) and reaction heats $\Delta H$ (in $\mathrm{kcal} / \mathrm{mol}$ ) in the reaction of benzothiophene (BT) with cyclopentadienyl radical (CPDyl). $\Delta H$ has been calculated at $0 \mathrm{~K}$. 

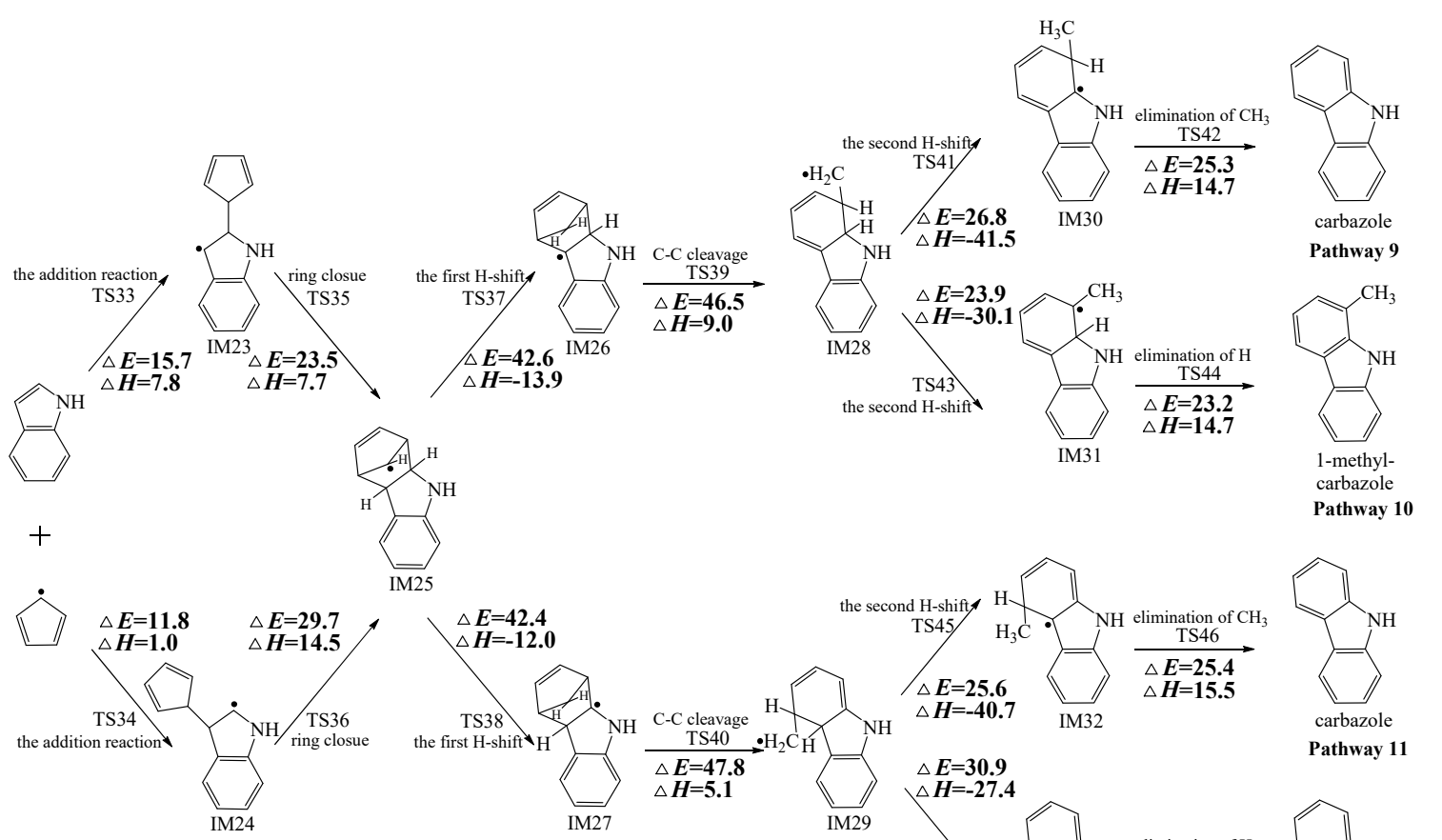

Figure 4. Carbazole (CA) formation routes embedded with the activation barriers $\Delta E$ (in $\mathrm{kcal} / \mathrm{mol}$ ) and reaction heats $\Delta H$ (in $\mathrm{kcal} / \mathrm{mol}$ ) in the reaction of indole (IN) with cyclopentadienyl radical (CPDyl). $\Delta H$ has been calculated at $0 \mathrm{~K}$.

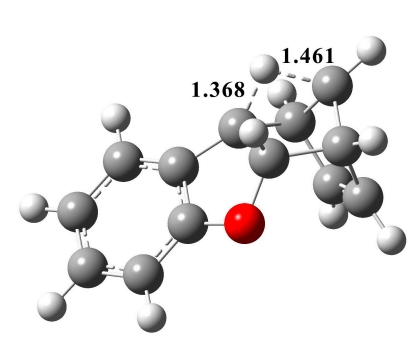

TS5

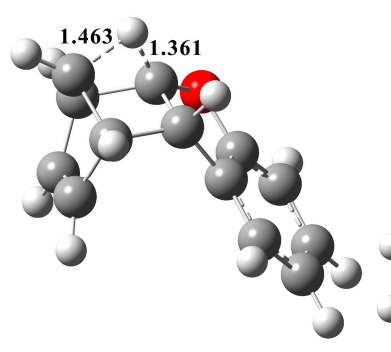

TS6

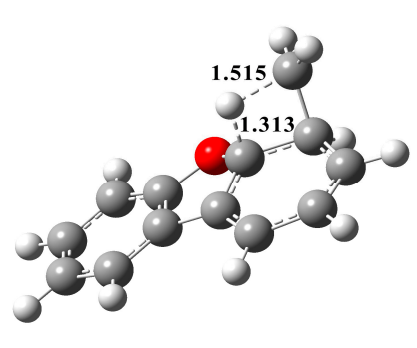

TS9

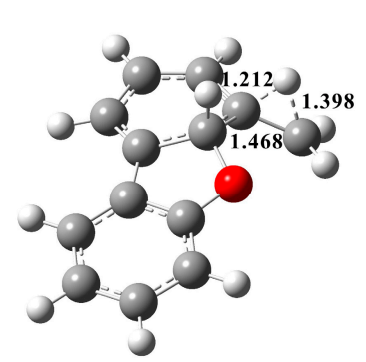

TS11

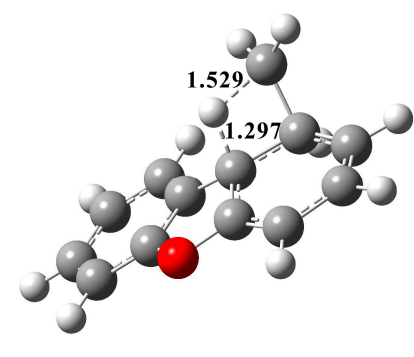

TS13

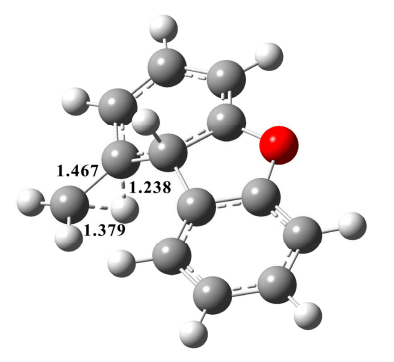

TS15

Figure 5. The structures and the geometrical parameters for the first/second H-shift transition states in the dibenzofuran (DBF) formation routes from the reaction of benzofuran (BF) with cyclopentadienyl radical (CPDyl). Distances are in angstroms. 


\subsection{Rate Constant Calculations}

It is difficult to measure the rate constants of the elementary reactions by experimental methods in the formation of dibenzo-NSO-HETs, especially the reactions involving the radicals and intermediates due to the short lifetime and lack of efficient detection schemes for these activated species. Direct dynamics calculations, that is, the calculation of rate constants or other dynamic information directly from electronic structure calculations can be used as a substitution. The kinetic parameters of dibenzo-NSO-HETs formation routes from benzo-NSO-HETs with CPDyl can be used in the NSO-HET compound formation kinetic model to predict the potential emissions and harm to the environment. In this section, the rate constants of the elementary reactions for the formation of dibenzo-NSO-HETs from benzo-NSO-HETs with CPDyl were calculated using canonical variational transition state theory (CVT) with small-curvature tunneling (SCT) contribution over 600-1200 K by means of the POLYRATE 9.7 program [63-67]. The calculated rate constants are shown in Table S6 of the Supporting Information for every $100 \mathrm{~K}$ in $600-1200 \mathrm{~K}$.

Due to the absence of available experimental values, it was difficult to make a direct comparison of the calculated CVT/SCT rate constants with the experimental values for all the elementary reactions. In order to clarify the reliability of the kinetics calculation in this study, we compared the CVT/SCT rate constants with the rate constant values available in the literature for the reaction of $\mathrm{C}_{6} \mathrm{H}_{5} \mathrm{O} \rightarrow$ $\mathrm{C}_{5} \mathrm{H}_{5}+\mathrm{CO}$. The rate constants measured in previous experiments were in excellent agreement with our CVT/SCT values. For example, at $1200 \mathrm{~K}$, the CVT/SCT rate constant measured by Lin was $2.5 \times 10^{3} \mathrm{~s}^{-1}$ [68], which agreed well with the value of $2.6 \times 10^{3} \mathrm{~s}^{-1}$ found in this study. The rate constants of the rate-determining steps in Figures 2-4 were calculated with the help of transition state theory (TST) by using Gibbs thermal corrections at high temperatures in combination with the Eyring equation $[45,69]$. In general, the TST rate constants were slightly larger than the CVT/SCT values. For example, at $1000 \mathrm{~K}$, the TST rate constants were $2.2 \times 10^{3} \mathrm{~s}^{-1}, 8.0 \times 10^{3} \mathrm{~s}^{-1}$, and $2.8 \times 10^{3} \mathrm{~s}^{-1}$ of the rate-determining steps for DBF, DBT, and CA formation, respectively, while the CVT/SCT values were $8.1 \times 10^{2} \mathrm{~s}^{-1}, 6.6 \times 10^{3} \mathrm{~s}^{-1}$, and $1.2 \times 10^{3} \mathrm{~s}^{-1}$ for DBF, DBT, and CA formation, respectively. The CVT/SCT method was also successfully used in polychlorinated dibenzofuran (PCDFs) and polychlorinated dibenzo-p-dioxin (PCDDs) formation from CPs, and polychlorinated dibenzothiophene (PCDTs) and polychlorinated thianthrene (PCTAs) formation from CTPs in our previous studies [45,69]. We hope our CVT/SCT calculations can provide the same excellent estimation accuracy for the crucial elementary reactions involved in the formation of dibenzo-NSO-HETs.

To improve the applicability, the rate constants were fitted, and Arrhenius formulas are given in Table 1 for the DBF formation routes from the reaction of BF with CPDyl, Table 2 for the DBT formation routes from the reaction of $\mathrm{BT}$ with $\mathrm{CPDyl}$ and Table 3 for the $\mathrm{CA}$ formation routes from the reaction of IN with CPDyl. The pre-exponential factor, the activation energy, and the rate constants can be obtained from these Arrhenius formulas.

Table 1. Arrhenius formulas for dibenzofuran (DBF) formation routes from the reaction of benzofuran (BF) with cyclopentadienyl radical (CPDyl) over the temperature range of $600-1200 \mathrm{~K}_{\text {(units are s}}{ }^{-1}$ and $\mathrm{cm}^{3}$ molecule $\mathrm{e}^{-1} \mathrm{~s}^{-1}$ for unimolecular and bimolecular reactions, respectively).

\begin{tabular}{ll}
\hline Reactions & Arrhenius Formulas \\
\hline benzofuran + cyclopentadieny $\rightarrow$ IM1 via TS1 & $k(\mathrm{~T})=\left(10.0 \times 10^{-25}\right) \exp (-12066.6 / \mathrm{T})$ \\
benzofuran + cyclopentadieny $\rightarrow$ IM1 via TS2 & $k(\mathrm{~T})=\left(1.2 \times 10^{-25}\right) \exp (-13171.4 / \mathrm{T})$ \\
$\mathrm{IM} 1 \rightarrow \mathrm{IM}$ via TS3 & $k(\mathrm{~T})=\left(3.0 \times 10^{11}\right) \exp (-5026.9 / \mathrm{T})$ \\
$\mathrm{IM} 2 \rightarrow$ IM3 via TS4 & $k(\mathrm{~T})=\left(2.6 \times 10^{13}\right) \exp (-10547.3 / \mathrm{T})$ \\
$\mathrm{IM} 3 \rightarrow$ IM4 via TS5 & $k(\mathrm{~T})=\left(9.2 \times 10^{12}\right) \exp (-23362.2 / \mathrm{T})$ \\
$\mathrm{IM} 3 \rightarrow$ IM5 via TS6 & $k(\mathrm{~T})=\left(1.0 \times 10^{13}\right) \exp (-23976.6 / \mathrm{T})$ \\
$\mathrm{IM} 4 \rightarrow$ IM6 via TS7 & $k(\mathrm{~T})=\left(4.9 \times 10^{13}\right) \exp (-24826.0 / \mathrm{T})$ \\
$\mathrm{IM} 5 \rightarrow$ IM7 via TS8 & $k(\mathrm{~T})=\left(5.1 \times 10^{11}\right) \exp (-22376.3 / \mathrm{T})$ \\
\hline
\end{tabular}


Table 1. Cont.

\begin{tabular}{ll}
\hline Reactions & Arrhenius Formulas \\
\hline IM6 $\rightarrow$ IM8 via TS9 & $k(\mathrm{~T})=\left(7.0 \times 10^{12}\right) \exp (-15749.0 / \mathrm{T})$ \\
$\mathrm{IM} 8 \rightarrow$ dibenzofuran $+\mathrm{CH}_{3}$ via TS10 & $k(\mathrm{~T})=\left(5.2 \times 10^{13}\right) \exp (-12901.2 / \mathrm{T})$ \\
$\mathrm{IM} 6 \rightarrow$ IM9 via TS11 & $k(\mathrm{~T})=\left(8.4 \times 10^{12}\right) \exp (-15584.3 / \mathrm{T})$ \\
$\mathrm{IM} 9 \rightarrow$ 4-methyl-dibenzofuran + H via TS12 & $k(\mathrm{~T})=\left(1.6 \times 10^{13}\right) \exp (-11575.9 / \mathrm{T})$ \\
$\mathrm{IM} 7 \rightarrow$ IM10 via TS13 & $k(\mathrm{~T})=\left(2.7 \times 10^{12}\right) \exp (-13593.4 / \mathrm{T})$ \\
$\mathrm{IM} 10 \rightarrow$ dibenzofuran $+\mathrm{CH}_{3}$ via TS14 & $k(\mathrm{~T})=\left(6.8 \times 10^{13}\right) \exp (-13629.3 / \mathrm{T})$ \\
$\mathrm{IM} 7 \rightarrow$ IM11 via TS15 & $k(\mathrm{~T})=\left(7.8 \times 10^{12}\right) \exp (-13970.9 / \mathrm{T})$ \\
$\mathrm{IM} 11 \rightarrow$ 2-methyl-dibenzofuran $+\mathrm{H}$ via TS16 & $k(\mathrm{~T})=\left(2.5 \times 10^{13}\right) \exp (-10298.0 / \mathrm{T})$ \\
\hline
\end{tabular}

Table 2. Arrhenius formulas for dibenzothiophene (DBT) formation routes from the reaction of benzothiophene (BT) with cyclopentadienyl radical (CPDyl) over the temperature range of 600-1200 K (units are $\mathrm{s}^{-1}$ and $\mathrm{cm}^{3}$ molecule $\mathrm{e}^{-1} \mathrm{~s}^{-1}$ for unimolecular and bimolecular reactions, respectively).

\begin{tabular}{ll}
\hline Reactions & Arrhenius Formulas \\
\hline benzothiophene + cyclopentadieny $\rightarrow$ IM12 via TS17 & $k(\mathrm{~T})=\left(3.0 \times 10^{-25}\right) \exp (-10457.6 / \mathrm{T})$ \\
benzothiophene + cyclopentadieny $\rightarrow$ IM13 via TS18 & $k(\mathrm{~T})=\left(2.1 \times 10^{-24}\right) \exp (-10618.3 / \mathrm{T})$ \\
$\mathrm{IM} 12 \rightarrow$ IM14 via TS19 & $k(\mathrm{~T})=\left(3.3 \times 10^{11}\right) \exp (-14334.0 / \mathrm{T})$ \\
$\mathrm{IM} 13 \rightarrow$ IM14 via TS20 & $k(\mathrm{~T})=\left(2.6 \times 10^{11}\right) \exp (-12339.6 / \mathrm{T})$ \\
$\mathrm{IM} 14 \rightarrow$ IM15 via TS21 & $k(\mathrm{~T})=\left(1.7 \times 10^{13}\right) \exp (-21731.2 / \mathrm{T})$ \\
$\mathrm{IM} 14 \rightarrow$ IM16 via TS22 & $k(\mathrm{~T})=\left(1.5 \times 10^{13}\right) \exp (-21514.7 / \mathrm{T})$ \\
$\mathrm{IM} 15 \rightarrow$ IM17 via TS23 & $k(\mathrm{~T})=\left(9.8 \times 10^{13}\right) \exp (-23422.3 / \mathrm{T})$ \\
$\mathrm{IM} 16 \rightarrow$ IM18 via TS24 & $k(\mathrm{~T})=\left(1.2 \times 10^{14}\right) \exp (-23936.3 / \mathrm{T})$ \\
$\mathrm{IM} 17 \rightarrow$ IM19 via TS25 & $k(\mathrm{~T})=\left(1.8 \times 10^{12}\right) \exp (-14289.8 / \mathrm{T})$ \\
$\mathrm{IM} 19 \rightarrow$ dibenzothiophene $+\mathrm{CH}_{3}$ via TS26 & $k(\mathrm{~T})=\left(5.2 \times 10^{13}\right) \exp (-13461.3 / \mathrm{T})$ \\
$\mathrm{IM} 17 \rightarrow$ IM20 via TS27 & $k(\mathrm{~T})=\left(5.8 \times 10^{12}\right) \exp (-12699.8 / \mathrm{T})$ \\
$\mathrm{IM} 20 \rightarrow$ 4-methyl-dibenzothiophene $+\mathrm{H}$ via TS28 & $k(\mathrm{~T})=\left(2.5 \times 10^{13}\right) \exp (-12510.8 / \mathrm{T})$ \\
$\mathrm{IM} 18 \rightarrow$ IM21 via TS29 & $k(\mathrm{~T})=\left(2.8 \times 10^{13}\right) \exp (-12756.2 / \mathrm{T})$ \\
$\mathrm{IM} 21 \rightarrow$ dibenzothiophene $+\mathrm{CH}_{3}$ via TS30 & $k(\mathrm{~T})=\left(8.9 \times 10^{13}\right) \exp (-13857.5 / \mathrm{T})$ \\
$\mathrm{IM} 18 \rightarrow$ IM22 via TS31 & $k(\mathrm{~T})=\left(6.8 \times 10^{12}\right) \exp (-15889.8 / \mathrm{T})$ \\
$\mathrm{IM} 22 \rightarrow$ 2-methyl-dibenzothiophene $+\mathrm{H}$ via TS32 & $k(\mathrm{~T})=\left(1.7 \times 10^{13}\right) \exp (-10615.2 / \mathrm{T})$ \\
\hline
\end{tabular}

Table 3. Arrhenius formulas for carbazole (CA) formation routes from the reaction of indole (IN) with cyclopentadienyl radical (CPDyl) over the temperature range of 600-1200 K (units are s${ }^{-1}$ and cm ${ }^{3}$ molecule ${ }^{-1} \mathrm{~s}^{-1}$ for unimolecular and bimolecular reactions, respectively).

\begin{tabular}{|c|c|}
\hline Reactions & Arrhenius Formulas \\
\hline indole + cyclopentadieny $\rightarrow$ IM23 via TS33 & $k(\mathrm{~T})=\left(1.1 \times 10^{-24}\right) \exp (-11654.9 / \mathrm{T})$ \\
\hline indole + cyclopentadieny $\rightarrow$ IM24 via TS34 & $k(\mathrm{~T})=\left(1.8 \times 10^{-24}\right) \exp (-8209.2 / \mathrm{T})$ \\
\hline IM23 $\rightarrow$ IM25 via TS35 & $k(\mathrm{~T})=\left(5.8 \times 10^{10}\right) \exp (-11877.8 / \mathrm{T})$ \\
\hline IM24 $\rightarrow$ IM25 via TS36 & $k(\mathrm{~T})=\left(2.0 \times 10^{11}\right) \exp (-14906.8 / \mathrm{T})$ \\
\hline IM25 $\rightarrow$ IM26 via TS37 & $k(\mathrm{~T})=\left(1.6 \times 10^{13}\right) \exp (-22274.5 / \mathrm{T})$ \\
\hline IM25 $\rightarrow$ IM27 via TS38 & $k(\mathrm{~T})=\left(1.5 \times 10^{13}\right) \exp (-21960.5 / \mathrm{T})$ \\
\hline IM26 $\rightarrow$ IM28 via TS39 & $k(\mathrm{~T})=\left(4.3 \times 10^{13}\right) \exp (-24215.9 / \mathrm{T})$ \\
\hline IM27 $\rightarrow$ IM29 via TS40 & $k(\mathrm{~T})=\left(4.5 \times 10^{13}\right) \exp (-25026.4 / \mathrm{T})$ \\
\hline IM28 $\rightarrow$ IM30 via TS41 & $k(\mathrm{~T})=\left(6.2 \times 10^{10}\right) \exp (-10484.5 / \mathrm{T})$ \\
\hline IM30 $\rightarrow$ carbazole $+\mathrm{CH}_{3}$ via TS42 & $k(\mathrm{~T})=\left(8.1 \times 10^{13}\right) \exp (-13792.3 / \mathrm{T})$ \\
\hline IM28 $\rightarrow$ IM31 via TS43 & $k(\mathrm{~T})=\left(3.7 \times 10^{12}\right) \exp (-11906.8 / \mathrm{T})$ \\
\hline IM31 $\rightarrow$ 4-methyl-carbazole $+\mathrm{H}$ via TS44 & $k(\mathrm{~T})=\left(2.3 \times 10^{13}\right) \exp (-10279.5 / \mathrm{T})$ \\
\hline IM29 $\rightarrow$ IM32 via TS45 & $k(\mathrm{~T})=\left(2.0 \times 10^{12}\right) \exp (-13357.4 / \mathrm{T})$ \\
\hline IM32 $\rightarrow$ carbazole $+\mathrm{CH}_{3}$ via TS46 & $k(\mathrm{~T})=\left(7.6 \times 10^{13}\right) \exp (-13643.4 / \mathrm{T})$ \\
\hline IM29 $\rightarrow$ IM33 via TS47 & $k(\mathrm{~T})=\left(6.4 \times 10^{12}\right) \exp (-15841.1 / \mathrm{T})$ \\
\hline IM33 $\rightarrow$ 2-methyl-carbazole $+\mathrm{H}$ via TS48 & $k(\mathrm{~T})=\left(2.7 \times 10^{13}\right) \exp (-10075.0 / \mathrm{T})$ \\
\hline
\end{tabular}




\section{Discussion}

\subsection{Reactions of Benzofuran, Benzothiophene, and Indole with Cyclopentadienyl}

As presented in Figure 2, pathways 1-2 from the first C11-H shift step shared an identical rate-determining reaction ( $\mathrm{C}-\mathrm{C}$ cleavage), and pathways $3-4$ from the first $\mathrm{C} 10-\mathrm{H}$ shift step also shared the same rate-determining reactions ( $\mathrm{C}-\mathrm{C}$ cleavage). The activation barrier of the rate-determining step of pathways 1-2 involved in the reaction of BF with CPDyl radical processed amounted to $47.2 \mathrm{kcal} / \mathrm{mol}$, which was generally lower than that of the rate-determining step $(50.7 \mathrm{kcal} / \mathrm{mol}) \mathrm{in}$ pathways 3-4. Therefore, pathways 1-2, forming DBF and 1-methyl-DBF, were enthalpically preferable over pathways 3-4, forming DBF and 4-methyl-DBF, in Figure 2. Thus, 1-methyl-DBF was much easier to generate than 4-methyl-DBF. Similar conclusions were obtained in the reactions of BT with CPDyl in Figure 3 and of IN with CPDyl in Figure 4. The C-C cleavage in pathways 5-6, resulting in the formation of DBT and 1-methyl-DBT, had a relatively lower activation barrier $(44.6 \mathrm{kcal} / \mathrm{mol})$ than that in pathways 7-8, resulting in the formation of DBT and 4-methyl-DBT, which indicated that pathways 5-6 are more labile than pathways 7-8 in the reaction of DBT with CPDyl. Analogously, pathways 9-10, forming CA and 1-methyl-CA, were overwhelmingly superior to pathways 11 and 12, forming CA and 4-methyl-CA, in the reaction of In with CPDyl in Figure 4, and the activation barriers of the C-C cleavage step were 46.5 and $47.8 \mathrm{kcal} / \mathrm{mol}$ in pathways $9-10$ and pathways $11-12$, respectively. Therefore, 1-methyl-DBT and 1-methyl-CA were more easily formed than 4-methyl-DBT and 4-methyl-CA, respectively.

Comparing pathway 1 and pathway 2, the activation barrier of the second ortho $\mathrm{C}-\mathrm{H}$ shift in pathway $2(28.4 \mathrm{kcal} / \mathrm{mol})$ was lower than that of the second same $\mathrm{C}-\mathrm{H}$ shift in pathway $1(28.7 \mathrm{kcal} / \mathrm{mol})$. In addition, the elimination of $\mathrm{H}$ step in pathway 2 required a lower activation barrier of $(22.3 \mathrm{kcal} / \mathrm{mol})$ to be overcome than that of elimination of $\mathrm{CH}_{3}$ in pathway $1(24.9 \mathrm{kcal} / \mathrm{mol})$. Thus, pathway 2, resulting in 1-methyl-DBF formation, was overwhelmingly superior to pathway, 1 resulting in the DBF formation. For pathways 3-4, the second same C-H shift step involved in the pathway 3 (activation barrier $26.3 \mathrm{kcal} / \mathrm{mol}$, reaction heat $-40.2 \mathrm{kcal} / \mathrm{mol}$ ) had a relatively lower barrier and was much more exothermic compared to the second ortho $\mathrm{C}-\mathrm{H}$ shift step involved in pathway 4 (activation barrier $26.9 \mathrm{kcal} / \mathrm{mol}$, reaction heat $-26.9 \mathrm{kcal} / \mathrm{mol}$ ). However, the unimolecular elimination of $\mathrm{CH}_{3}$ involved in pathway 3 (activation barrier $25.9 \mathrm{kcal} / \mathrm{mol}$, reaction heat $15.9 \mathrm{kcal} / \mathrm{mol}$ ) had a relatively higher barrier and was much more endoergic than the unimolecular elimination of $\mathrm{H}$ involved in pathway 4 (activation barrier $19.2 \mathrm{kcal} / \mathrm{mol}$, reaction heat $9.7 \mathrm{kcal} / \mathrm{mol}$ ). Thus, pathway 3 and pathway 4 were competitive, which means that both DBF and 4-methyl-DBF can be formed competitively. Above all, although 1-methyl-DBF formation was preferred over DBF formation from the view of energetic values, 1-methyl-DBF formation had one less formation route than DBF formation. Thus, 1-methyl-DBF and DBF were inferred to be produced competitively, and to be more liable to form than 4-methyl-DBF. Further direct experimental observation will be needed to verify the yields of DBF, 1-methyl-DBF, and 4-methyl-DBF. Analogously, pathway 6 was favored over pathway 5 in Figure 3; pathway 7 and pathway 8 were competitive in Figure 3; pathway 10 was favored over pathway 9 in Figure 4; and pathway 11 and pathway 12 were competitive in Figure 4 . Therefore, the main products of DBT formation from the reaction of BT with CPDyl are DBT and 1-methyl-DBT, and the main products of CA formation from the reaction of IN with CPDyl are carbazole and 1-methyl-CA.

Comparison of DBF and methyl-DBF formation from BF with CPDyl, DBT and methyl-DBT formation from BT with CPDyl, and CA and methyl-CA formation from IN with CPDyl, as denoted in Figures 2-4, clearly showed that the effect of the $\mathrm{O}, \mathrm{S}$, and $\mathrm{N}$ atom heterocycle of the benzo-NSO-HETs had a significant influence on dibenzo-NSO-HET formation. For the pathways from the first C11-H shift in Figures 2-4, the activation barriers of the rate-determining step of $\mathrm{O}$ heterocycle pathways, $\mathrm{S}$ heterocycle pathways, and $\mathrm{N}$ heterocycle pathways were $47.2 \mathrm{kcal} / \mathrm{mol}, 44.6 \mathrm{kcal} / \mathrm{mol}$, and $46.5 \mathrm{kcal} / \mathrm{mol}$, respectively. In addition, for the pathways from the first $\mathrm{C} 10-\mathrm{H}$ shift in Figures 2-4, the activation barriers of the rate-determining steps of $\mathrm{O}$ heterocycle pathways, $\mathrm{S}$ heterocycle pathways, and $\mathrm{N}$ heterocycle 
pathways were $50.7 \mathrm{kcal} / \mathrm{mol}, 45.5 \mathrm{kcal} / \mathrm{mol}$, and $47.8 \mathrm{kcal} / \mathrm{mol}$, respectively. Thus, the ranking of the dibenzo-NSO-HET formation potential is as follows: sulfureted heterocycle compounds $>$ nitrided heterocycle compounds > oxygenated heterocycle compounds, i.e., DBT and methyl-DBT formation $>$ DBF and methyl-DBF formation $>$ CA and methyl-CA formation. It is also interesting to compare the reaction pathways denoted in Figures 2-4 with our previous research on naphthalene with CPDyl [45]. The activation barriers of the rate-determining steps for phenanthrene and methyl-phenanthrene formation from the reaction of naphthalene with CPDyl were 42.0-43.2 kcal $/ \mathrm{mol}$, i.e., lower than those of dibenzo-NSO-HET formation from benzo-NSO-HETs with CPDyl (44.6-50.7 kcal/mol). However, the activation barriers of the rate-determining steps for anthracene and methyl-anthracene formation $(52.9 \mathrm{kcal} / \mathrm{mol})$ were higher than those of dibenzo-NSO-HET formation from benzo-NSO-HETs with CPDyl. This may imply that the reactions of CPDyl attacking benzene rings are enthalpically competitive with reactions of CPDyl added onto furan/thiophene/pyrrole rings under pyrolysis or combustion conditions.

\subsection{Rate Constant Calculations}

To confirm the possible routes of dibenzo-NSO-HET formation from benzo-NSO-HETs with CPDyl, it is important to compare the CVT/SCT rate constants of the rate-determining step in each pathway. At a given temperature, the calculated CVT/SCT rate constants for the rate-determining steps in pathways $1-2$, pathways $5-6$, and pathways $9-10$ were larger than those of pathways 3-4, pathways $7-8$, and pathways $11-12$, respectively. For example, at $800 \mathrm{~K}$, the calculated CVT/SCT rate constant was $1.6 \mathrm{~s}^{-1}$ for the rate-determining step in the pathways $1-2$, whereas the value was $3.6 \times 10^{-1} \mathrm{~s}^{-1}$ for the rate-determining step in pathways 3-4 for the formation of DBF and methyl-DBF from BF with CPD. At $1000 \mathrm{~K}$, the calculated CVT/SCT rate constant was $6.6 \times 10^{3} \mathrm{~s}^{-1}$ for the rate-determining step in pathways $5-6$, whereas the value was $4.7 \times 10^{3} \mathrm{~s}^{-1}$ for the rate-determining step in pathways $7-8$ for the formation of DBT and methyl-DBT from BT with CPDyl. Similarly, at $1200 \mathrm{~K}$, the calculated CVT/SCT rate constant in pathways 9-10 was $7.4 \times 10^{4} \mathrm{~s}^{-1}$, which was larger than that in pathways 11-12 $\left(4.0 \times 10^{4} \mathrm{~s}^{-1}\right)$ for the formation of CA and methyl-CA from IN with CPDyl. All these comparisons agree well with the conclusions outlined above.

For the formation of dibenzo-NSO-HET from the reactions of benzo-NSO-HETs with the CPDyl, pathways 1,5, and 9 were favored over pathways 2, 6, and 10, respectively; pathways 3, 7, and 11 were competitive with pathways 4,8 , and 12 , respectively. This conclusion was also supported by comparing the CVT/SCT rate constants of the last two steps of these pathways. For example, for the formation of DBT and methyl-DBT in pathway $5-6$, the calculated CVT/SCT rate constants was $1.1 \times 10^{6} \mathrm{~s}^{-1}$ for the reaction IM17 $\rightarrow$ IM19 via TS25 at $1000 \mathrm{~K}$, which was smaller than the value $1.8 \times 10^{7} \mathrm{~s}^{-1}$ for the IM17 $\rightarrow$ IM20 via TS27 at $1000 \mathrm{~K}$; the calculated CVT/SCT rate constant was $7.4 \times 10^{7} \mathrm{~s}^{-1}$ for the reaction IM19 $\rightarrow$ dibenzothiophene $+\mathrm{CH}_{3}$ via TS26 at $1000 \mathrm{~K}$, which was also smaller than the value $9.1 \times 10^{7} \mathrm{~s}^{-1}$ for the IM20 $\rightarrow$ 1-methyl-dibenzothiophene $+\mathrm{H}$ via TS28 at $1000 \mathrm{~K}$. This reconfirms the finding of the thermodynamic analysis: that pathway 6 resulting in 1-methyl-DBT was energetically favored over pathway 5 resulting in the DBT. For the formation of DBT and 4-methyl-DBT in pathway 7-8 at $800 \mathrm{~K}$, the calculated CVT/SCT rate constant of IM18 $\rightarrow$ IM21 via TS29 was $3.3 \times 10^{5} \mathrm{~s}^{-1}$, which was larger than the value $1.6 \times 10^{4} \mathrm{~s}^{-1}$ for IM18 $\rightarrow$ IM22 via TS31; the value of IM21 $\rightarrow$ dibenzothiophene $+\mathrm{CH}_{3}$ via TS30 was $2.6 \times 10^{6} \mathrm{~s}^{-1}$, which was smaller than the value $2.8 \times 10^{7} \mathrm{~s}^{-1}$ of IM22 $\rightarrow 4$-methyl-dibenzothiophene $+\mathrm{H}$ via TS32. This reconfirmed the thermodynamic analysis that both DBT and 4-methyl-DBT can be formed competitively.

For the pathways from the first $\mathrm{C} 11-\mathrm{H}$ shift or from the first $\mathrm{C} 10-\mathrm{H}$ shift in Figures 2-4, the CVT/SCT rate constants for the rate-determining step of $\mathrm{O}$ heterocycle pathways, $\mathrm{S}$ heterocycle pathways, and $\mathrm{N}$ heterocycle pathways were ranked as $S$ heterocycle pathways $>N$ heterocycle pathways $>$ O heterocycle pathways over the whole studied temperature range. For example, at $1000 \mathrm{~K}$, for the pathways from the first $\mathrm{C} 11-\mathrm{H}$ shift of reactions of BF, BT, and IN with CPD, the CVT/SCT rate constants for the rate-determining step were $8.1 \times 10^{2} \mathrm{~s}^{-1}, 6.6 \times 10^{3} \mathrm{~s}^{-1}$, and $1.2 \times 10^{3} \mathrm{~s}^{-1}$ for the reactions of $\mathrm{BF}$, BT, 
and IN with CPDyl, respectively; the value was $9.7 \times 10^{1} \mathrm{~s}^{-1}, 4.7 \times 10^{3} \mathrm{~s}^{-1}$, and $6.0 \times 10^{2} \mathrm{~s}^{-1}$ for the pathways from the first $\mathrm{C} 11-\mathrm{H}$ shift of reactions of $\mathrm{BF}, \mathrm{BT}$, and IN with CPDyl, respectively. This was consistent with the thermodynamic analysis: the ranking of the dibenzo-NSO-HET formation potential was sulfureted heterocycle compounds $>$ nitrided heterocycle compounds $>$ oxygenated heterocycle compounds.

\section{Materials and Methods}

\subsection{Density Functional Theory}

All the quantum chemical calculations on the structure, frequency, and energy of related substances such as reactants, products, intermediates, and transition state were performed using the Gaussian 09 program [70]. The geometry optimizations were conducted using the hybrid meta functional MPWB1K, which gives uniformly excellent performance for thermochemistry, thermochemical kinetics, hydrogen bonding, and weak interactions, with the standard $6-31+G(d, p)$ basis set [71]. The vibrational frequencies were also computed at the same level to determine the natures of the stationary points. Moreover, the intrinsic reaction coordinate (IRC) was calculated at the MPWB1K/6-31+G(d,p) level to verify that the transition state connected to the right minima along the reaction path [72]. In order to acquire more reliable energy information, a more flexible basis set, $6-311+G(3 d f, 2 p)$, was employed to determine the single point energies. All energies quoted and discussed in this paper include zero-point energy correction (ZPE).

\subsection{Kinetic Calculation}

To obtain the rate constants and activation energies, kinetic calculations were carried out the using POLYRATE 9.7 program [63]. The canonical variational transition state (CVT) theory with a small-curvature tunneling (SCT) contribution $[64,66,67]$ was applied to evaluate the theoretical rate constants for the elementary steps included in the reactions of BF, BT, and IN with CPDyl. The rate constants for each reaction were calculated over a wide temperature range (600-1200 K), which covered the possible DBF, DBT, and CA formation temperatures under pyrolysis or combustion conditions. To calculate the rate constants, 40 nonstationary points near the transition state along the MEP ( 20 points on the reactant side and 20 points on the product side) were selected for frequency calculations at the MPWB1K/6-31+G(d,p) level. The SSTEP, a variable keyword in the POLYRATE 9.7 program that specifies the step size along the mass-scaled MEP, was confirmed as 0.05. The SRANGE, which is required to specify the limits on the reaction coordinates, was selected as -1.5 to 1.5 . Parameters such as energy data, force constant matrices, hessian matrices, stationary point coordinates, and unstationary points were obtained from the Gaussian 09 program output files and were input into the POLYRATE 9.7 input files automatically by our self-compiled program.

\section{Conclusions}

In this study, the mechanisms of the homogeneous gas-phase formation of dibenzo-NSO-heterocycles (dibenzo-NSO-HETs), namely dibenzofuran (DBF), dibenzothiophene (DBT), and carbazole (CA), from benzo-NSO-heterocycles (benzo-NSO-HETs), namely benzofuran (BF), benzothiophene (BT), and indole (IN), with the cyclopentadienyl radical (CPDyl) were investigated theoretically using DFT electronic structure theory at the MPWB1K/6-311+G(3df,2p)//MPWB1K/6-31+G(d,p) level. Kinetic calculations were performed and the rate constants were calculated over the temperature range of $600-1200 \mathrm{~K}$ using canonical variational transition state (CVT) theory with the small-curvature tunneling (SCT) contribution. The rate temperature formulas were fitted. Several energetically preferred routes for dibenzo-NSO-HET formation were proposed. The obtained rate constant can support more detailed input parameters for the NSO-HETs control and prediction models. The effects of $\mathrm{O}, \mathrm{S}$, and $\mathrm{N}$ atoms on the formation potential for dibenzo-NSO-HET formation were sorted. Four specific conclusions were drawn. 
(1) The dibenzo-NSO-HETs growth mechanism involves six elementary steps: the addition reaction, ring closure, the first $\mathrm{H}$ shift, $\mathrm{C}-\mathrm{C}$ cleavage, the second $\mathrm{H}$ shift, and elimination of $\mathrm{CH}_{3}$ or $\mathrm{H}$. Due to its having the highest activation barrier and being strongly endothermic, the cleavage of the $\mathrm{C}-\mathrm{C}$ bond step was regarded as the rate-determining step for each pathway.

(2) For given dibenzo-NSO-HET formation, pathways from an initial C11-H shift step were preferred over pathways from an initial $\mathrm{C} 10-\mathrm{H}$ shift step. The formation of $\mathrm{C} 1$-methylated products was favored over that of C4-methylated products. DBF and 1-methyl-DBF, DBT and 1-methyl-DBT, and CA and 1-methyl-CA were the main products of reactions of BF, BT, and IN with CPDyl, respectively.

(3) The ranking of the dibenzo-NSO-HET formation potential from benzo-NSO-HETs with CPDyl was as follows: sulfureted heterocycle compounds $>$ nitrided heterocycle compounds $>$ oxygenated heterocycle compounds. The reactions of CPDyl attacking the benzene and furan/thiophene/pyrrole rings were inferred to be comparable under pyrolysis or combustion conditions.

Supplementary Materials: The following are available online at http://www.mdpi.com/1422-0067/20/21/5420/s1.

Author Contributions: X.L., Y.G. and F.X. designed and performed the mechanism calculations, then wrote the manuscript; X.L., Y.G., C.Z. and S.Z. performed the kinetic calculation. X.L., Y.G., Y.S. and Q.Z. all analyzed the data in the manuscript.

Funding: This work was supported by NSFC (National Natural Science Foundation of China, project Nos. 91644214,21677089, 21876102), Shenzhen Science and Technology Research and Development Funds (project Nos. JCYJ20160510165106371), FRFSDU (The Fundamental Research Funds of Shandong University, project Nos. 2016WLJH51, 2017JC033), the China Postdoctoral Science Foundation funded project (project Nos. 2017M612277, 2017T100493), SKLECRA (The open foundation of state key laboratory of environmental criteria and risk assessment, Chinese research academy of environmental sciences No. 2016OFP09). The authors thank Donald G. Truhlar for providing the POLYRATE 9.7 program.

\section{Abbreviations}

$\begin{array}{ll}\text { DBF } & \text { dibenzofuran } \\ \text { DBT } & \text { dibenzothiophene } \\ \text { CA } & \text { carbazole } \\ \text { BF } & \text { benzofuran } \\ \text { BT } & \text { benzothiophene } \\ \text { IN } & \text { indole } \\ \text { NSO-HETs } & \text { nitrogen, sulfur, or oxygen heterocycles } \\ \text { PACs } & \text { polycyclic aromatic compounds } \\ \text { PAHs } & \text { polycyclic aromatic hydrocarbons } \\ \text { DFT } & \text { density functional theory } \\ \text { CVT } & \text { canonical variational transition state } \\ \text { SCT } & \text { small-curvature tunneling } \\ \text { CPDyl } & \text { cyclopentadienyl radical } \\ \text { ZPE } & \text { zero-point energy } \\ \text { IRC } & \text { intrinsic reaction coordinate }\end{array}$

\section{References}

1. Johansen, S.S.; Hansen, A.B.; Mosbæk, H.; Arvin, E. Identification of heteroaromatic and other organic compounds in ground water at creosote-contaminated sites in Denmark. Groundwater Monit. Remediat. 1997, 17, 106-115. [CrossRef]

2. Gichner, T. IARC monographs on the evaluation of carcinogenic risks to humans. Wood Dust and Formaldehyde. Biol. Plant. 1995, 37, 500. [CrossRef]

3. Bleeker, E.A.J.; Wiegman, S.; Voogt, P.D.; Kraak, M.; Admiraal, W. Toxicity of azaarenes. Rev. Environ. Contam. Toxicol. 2002, 173, 39-83. [PubMed]

4. Meyer, S.; Steinhart, H. Effects of heterocyclic PAHs (N, S, O) on the biodegradation of typical tar oil pahs in a soil/compost mixture. Chemosphere 2000, 40, 359-367. [CrossRef] 
5. Lopes, T.J.; Furlong, E.T. Occurrence and potential adverse effects of semivolatile organic compounds in streambed sediment, united states, 1992-1995. Environ. Toxicol. Chem. 2001, 20, 727-737.

6. Dyreborg, S.; Arvin, E.; Broholm, K. Biodegradation of NSO-compounds under different redox-conditions. J. Contam. Hydrol. 1997, 25, 177-197. [CrossRef]

7. Zhu, X.; Ni, J.; Lai, P. Advanced treatment of biologically pretreated coking wastewater by electrochemical oxidation using boron-doped diamond electrodes. Water Res. 2009, 43, 4347-4355. [CrossRef]

8. Anonymous. Dibenzofuran. In Dangerous Properties of Industrial Materials Report; Van Nostrand Reinhold: New York, NY, USA, 1995; Volume 15, pp. 45-58.

9. Elvers, B.; Hawkins, S.; Ravenscroft, M.; Rounsaville, J.F.; Schulz, G. Ullmann's Encyclopedia of Industrial Chemistry, 5th ed.; VCH Publishers: New York, NY, USA, 1989; Volume 12, pp. 130-133.

10. Roy, J.; Jana, A.K.; Mal, D. Recent trends in the synthesis of carbazoles: An update. Tetrahedron 2012, 68, 6099-6121. [CrossRef]

11. Nojiri, H.; Omori, T. Carbazole metabolism by Pseudomonads. In Pseudomonas; Ramos, J.L., Filloux, A., Eds.; Springer: New York, NY, USA, 2007; Volume 5, pp. 107-145.

12. Collin, G.; Hoke, H. Carbazole. In Ullman's Encyclopedia of Industrial Chemistry, 5th ed.; Elvers, B., Hawkins, S., Schultz, G., Eds.; Wiley-VCH: New York, NY, USA, 1986.

13. Seto, H. New 3-Hydroxy-4-Aminocarbazole Compounds. JP Patent 03227971, 1991.

14. Lim, B.R.; Hu, H.Y.; Fujie, K. Biological degradation and chemical oxidation characteristics of coke-oven wastewater. Water Air Soil Pollut. 2003, 146, 23-33. [CrossRef]

15. Zhang, M.; Tay, J.H.; Qian, Y.; Gu, X.S. Coke plant wastewater treatment by fixed biofilm system for COD and NH3-N removal. Water Res. 1998, 32, 519-527. [CrossRef]

16. Smith, J.H.; Mabey, W.R.; Bahonos, N.; Holt, B.R.; Lee, S.S.; Chou, T.W.; Venberger, D.C.; Mill, T. Environmental Pathways of Selected Chemicals in Freshwater Systems: Part II Laboratory Studies; Interagency Energy-Environment Research and Development Program Report; EPA-600/7-78-074; US Environmental Protection Agency: Athens, GA, USA, 1978.

17. Jacobs, B.W.; Billings, C.E. Characterization and temperature dependence of PAH emissions from a simulated rubber combustion operation. Am. Ind. Hyg. Assoc. J. 1985, 46, 547-554. [CrossRef] [PubMed]

18. Perreira, W.E.; Rostard, C.E.; Updegraft, D.L.; Bennett, J.M. Fate and movement of azaarenes and their anaerobic biotransformation products in an aquifer contaminated by wood-treatment chemicals. Environ. Toxicol. Chem. 1987, 6, 163-176. [CrossRef]

19. Ishikawa, S.; Sakazaki, Y.; Eguchi, Y.; Suetomi, R.; Nakamura, E. Identification of chemical substances in industrial wastes and their pyrolytic decomposition products. Chemosphere 2005, 59, 1343-1353. [CrossRef]

20. Dartiguelongue, C.; Behar, F.; Budzinski, H.; Scacchi, G.; Marquaire, P.M. Thermal stability of dibenzothiophene in closed system pyrolysis: Experimental study and kinetic modelling. Org. Geochem. 2006, 37, 98-116. [CrossRef]

21. Sobkowiak, M.; Griffith, J.M.; Wang, B.; Beaver, B. Insight into the mechanisms of middle distillate fuel oxidative degradation. Part 1: On the role of phenol, indole, and carbazole derivatives in the thermal oxidative stability of Fischer-Tropsch/petroleum jet fuel blends. Energy Fuel 2009, 23, 2041-2046. [CrossRef]

22. Freitas, V.L.; Gomes, J.R.; DaSilva, M.D.R. Dibenzofuran and methyldibenzofuran derivatives: Assessment of thermochemical data. Struct. Chem. 2013, 24, 1923-1933. [CrossRef]

23. Gu, Y.; Yperman, J.; Reggers, G.; Carleer, R.; Vandewijngaarden, J. Characterisation of volatile organic sulphur compounds release during coal pyrolysis in inert, hydrogen and $\mathrm{CO}_{2}$ atmosphere. Fuel 2016, 184, 304-313. [CrossRef]

24. Wikström, E.; Marklund, S. Secondary formation of chlorinated dibenzo-p-dioxins, dibenzofurans, biphenyls, benzenes, and phenols during MSW combustion. Environ. Sci. Technol. 2000, 34, 604-609. [CrossRef]

25. Melius, C.F.; Colvin, M.E.; Marinov, N.M.; Pitz, W.J.; Senkan, S.M. Reaction mechanisms in aromatic hydrocarbon formation involving the $\mathrm{C}_{5} \mathrm{H}_{5}$ cyclopentadienyl. Symp. Combust. 1996, 26, 685-692. [CrossRef]

26. Rebbert, R.E.; Chesler, S.N.; Guenther, F.R.; Parris, R.M. Liquid chromatography-gas chromatography procedure to determine the concentration of dibenzothiophene in a crude oil matrix. J. Chromatogr. A 1984, 284, 211-217. [CrossRef]

27. Soliman, Y.S.; Al Ansari, E.M.S.; Wade, T.L. Concentration, composition and sources of PAHs in the coastal sediments of the exclusive economic zone (EEZ) of Qatar, Arabian Gulf. Mar. Pollut. Bull. 2014, 85, 542-548. [CrossRef] [PubMed] 
28. Gieg, L.M.; Otter, A.; Fedorak, P.M. Carbazole degradation by Pseudomonas sp. LD2: Metabolic characteristics and the identification of some metabolites. Environ. Sci. Technol. 1996, 30, 575-585. [CrossRef]

29. Blum, P.; Sagner, A.; Tiehm, A.; Martus, P.; Wendel, T.; Grathwohl, P. Importance of heterocylic aromatic compounds in monitored natural attenuation for coal tar contaminated aquifers: A review. J. Contam. Hydrol. 2011, 126, 181-194. [CrossRef] [PubMed]

30. Calkins, W.H. Investigation of organic sulfur-containing structures in coal by flash pyrolysis experiments. Energy Fuel 1987, 1, 59-64. [CrossRef]

31. Asif, M.; Alexander, R.; Fazeelat, T.; Pierce, K. Geosynthesis of dibenzothiophene and alkyl dibenzothiophenes in crude oils and sediments by carbon catalysis. Org. Geochem. 2009, 40, 895-901. [CrossRef]

32. Richter, H.; Howard, J.B. Formation of polycyclic aromatic hydrocarbons and their growth to soot-a review of chemical reaction pathways. Prog. Energy Combust. 2000, 26, 565-608. [CrossRef]

33. Lindstedt, P.; Maurice, L.; Meyer, M. Thermodynamic and kinetic issues in the formation and oxidation of aromatic species. Faraday Discuss. 2001, 119, 409-432. [CrossRef]

34. Hansen, N.; Klippenstein, S.J.; Miller, J.A.; Wang, J.; Cool, T.A.; Law, M.E.; Westmoreland, P.R.; Kasper, T.; Kohse-Hoinghaus, K. Identification of $\mathrm{C}_{5} \mathrm{H}_{\mathrm{x}}$ isomers in fuel-rich flames by photoionization mass spectrometry and electronic structure calculations. J. Phys. Chem. 2006, 110, 4376-4388. [CrossRef]

35. Winkler, J.K.; Karow, W.; Rademacher, P. Gas phase pyrolysis of heterocyclic compounds, part 4: Flow pyrolysis and annulation reactions of some oxygen heterocycles: Furan, benzo[b]furan and dibenzofuran. A product oriented study. J. Anal. Appl. Pyrol. 2001, 57, 133-144. [CrossRef]

36. Freitas, V.L.S.; Gomes, J.R.B.; da Silva, M.D.M.C.R. Revisiting dibenzothiophene thermochemical data: Experimental and computational studies. J. Chem. Thermodyn. 2009, 41, 1199-1205. [CrossRef]

37. Burcat, A.; Dvinyaninov, M. Detailed kinetics of cyclopentadiene decomposition studied in a shock tube. Int. J. Chem. Kinet. 1997, 29, 505-514. [CrossRef]

38. Lin, C.Y.; Lin, M.C. Thermal decomposition of methyl phenyl ether in shock waves: The kinetics of phenoxy radical reactions. J. Phys. Chem. 1986, 90, 425-431. [CrossRef]

39. Lamprecht, A.; Atakan, B.; Kohse-Hoinghaus, K. Fuel-rich flame chemistry in low-pressure cyclopentene flames. Proc. Combust. Inst. 2000, 28, 1817-1824. [CrossRef]

40. Lu, M.M.; Mulholland, J.A. Aromatic hydrocarbon growth from indene. Chemosphere 2001, 42, 625-633. [CrossRef]

41. Manion, J.A.; Louw, R. Rates, products, and mechanisms in the gas-phase hydrogenolysis of phenol between 922 and 1175 K. J. Phys. Chem. 1989, 93, 3563-3574. [CrossRef]

42. Mulholland, J.A.; Lu, M.; Kim, D.H. Pyrolytic growth of polycyclic aromatic hydrocarbons by cyclopentadienyl moieties. Proc. Combust. Inst. 2000, 28, 2593-2599. [CrossRef]

43. Ikeda, E.; Tranter, R.S.; Kiefer, J.H.; Kern, R.D.; Singh, H.J.; Zhang, Q. The pyrolysis of methylcyclopentadiene: Isomerization and formation of aromatics. Proc. Combust. Inst. 2000, 28, 1725-1732. [CrossRef]

44. Butler, R.G.; Glassman, I. Cyclopentadiene combustion in a plug flow reactor near 1150 K. Proc. Combust. Inst. 2009, 32, 395-402. [CrossRef]

45. Xu, F.; Shi, X.; Zhang, Q.; Wang, W. Mechanism for the growth of polycyclic aromatic hydrocarbons from the reactions of naphthalene with cyclopentadienyl and indenyl. Chemosphere 2016, 162, 345-354. [CrossRef]

46. Maris, A.; Giuliano, B.M.; Melandri, S.; Ottaviani, P.; Caminati, W.; Favero, L.B.; Velino, B. Structure, dipole moment and large amplitude motions of 1-benzofuran. Phys. Chem. Chem. Phys. 2005, 7, 3317-3322. [CrossRef]

47. El-Azhary, A.A. A DFT study of the geometries and vibrational spectra of indene and some of its heterocyclic analogues, benzofuran, benzoxazole, bensothiophene, benzothiazole, indole and indazole. Spectrochim. Acta A 1999, 55, 2437-2446. [CrossRef]

48. Banerjee, A. The crystal and molecular structure of dibenzofuran. Acta Crystallogr. B 1973, 139, 415-423. [CrossRef]

49. Schaffrin, R.M.; Trotter, J. Structure of dibenzothiophen. J. Chem. Soc. A Inorg. Phys. Theor. 1970, 1561-1565. [CrossRef]

50. Lee, S.Y.; Boo, B.H. Molecular structures and vibrational spectra of pyrrole and carbazole by density functional theory and conventional, ab initio calculations. J. Phys. Chem. 1996, 100, 15073-15078. [CrossRef]

51. Collier, W.B.; Klots, T.D. Heteroatom derivatives of indene. part 1. vibrational frequencies and a refined scaled overlay of the am1 force field of indole, benzofuran benzothiophene, benzoxazole and benzothiazole. Spectrochim. Acta A 1995, 51, 1255-1272. [CrossRef] 
52. Ljubic, I.; Sabljic, A. Theoretical study of structure, vibrational frequencies, and electronic spectra of dibenzofuran and its polychlorinated derivatives. J. Phys. Chem. A 2007, 111, 1339-1350. [CrossRef]

53. Lee, S.Y. Density functional theory calculation of molecular structure and vibrational spectra of dibenzothiophene in the ground and the lowest triplet state. J. Phys. Chem. A 2001, 105, 8093-8097. [CrossRef]

54. Bree, A.; Zwarich, R. Vibrational assignment of carbazole from infrared, raman, and fluorescence spectra. J. Chem. Phys. 1968, 49, 3344-3355. [CrossRef]

55. Steele, W.V.; Chirico, R.D. Thermodynamics and the hydrodeoxygenation of 2,3-Benzofuran. In Cooperative Agreement No. FC22-83FE60149 (NIPEP-457); IIT Research Institute, NIPEP: Bartlesville, OK, USA, 1990; pp. 1-75.

56. Sabbah, R. Thermodynamique de substances soufrees. I. Etude thermochimique du benzo-2,3 thiophene et du dibenzothiophene. Bull. Soc. Chim. France 1979, 9, 434-437.

57. Das, A.; Frenkel, M.; Gadalla, N.A.M.; Kudchadker, S.; Marsh, K.N.; Rodgers, A.S. Thermodynamic and thermophysical properties of organic nitrogen compounds. part II. 1- and 2-butanamine, 2-methyl-1-propanamine, 2-methyl-2-propanamine, pyrrole, 1-,2-, and 3-methylpyrrole, pyridine, 2-,3-, and 4-methylpyridine, pyrrolidine, piperidine, indole, quinoline, isoquinoline, acridine, carbazole, phenanthridine, 1- and 2-naphthalenamine, and 9-methylcarbazole. J. Phys. Chem. Ref. Data 1993, 22, 659.

58. Sabbah, R. Thermodynamic study of fluorene and dibenzofuran. Bull. Soc. Chim. France 1991, 128, 350.

59. Chirico, R.D.; Knipmeyer, S.E.; Nguyen, A.; Steele, W.V. The thermodynamic properties of dibenzothiophene. J. Chem. Thermodyn. 1991, 23, 431-450. [CrossRef]

60. Sabbah, R.; Antipine, I. Thermodynamic study on four polycycles. Relationship between their energy values and their structure. Bull. Soc. Chim. France 1987, 124, 392-400.

61. Roth, W.R.; Adamczak, O.; Breuckmann, R.; Lennartz, H.W.; Boese, R. Die Berechnung von Resonanzenergien; das MM2ERW-Kraftfeld. Eur. J. Inorg. Chem. 1991, 124, 2499-2521. [CrossRef]

62. Manion, J.A. Evaluated Enthalpies of Formation of the Stable Closed Shell C1 and C2 Chlorinated Hydrocarbons. J. Phys. Chem. Ref. Data 2002, 31, 123-172. [CrossRef]

63. Corchado, J.C.; Chuang, Y.Y.; Fast, P.L.; Hu, W.; Liu, Y.; Lynch, G.; Nguyen, K.; Jackels, C.; Fernandez-Ramos, A.; Ellingson, B. POLYRATE, Version 9.7; University of Minnesota: Minneapolis, MN, USA, 2007.

64. Baldridge, K.K.; Gordon, M.S.; Steckler, R.; Truhlar, D.G. Ab initio reaction paths and direct dynamics calculations. J. Phys. Chem. 1989, 93, 5107-5119. [CrossRef]

65. Fernandez-Ramos, A.; Ellingson, B.A.; Garret, B.C.; Truhlar, D.G. Variational transition state theory with multidimensional tunneling. Rev. Comput. Chem. 2007, 23, 125.

66. Garrett, B.C.; Truhlar, D.G. Generalized transition state theory. Classical mechanical theory and applications to collinear reactions of hydrogen molecules. J. Phys. Chem. 1979, 83, 1052-1079. [CrossRef]

67. Gonzalez-Lafont, A.; Truong, T.N.; Truhlar, D.G. Interpolated variational transition-state theory: Practical methods for estimating variational transition-state properties and tunneling contributions to chemical reaction rates from electronic structure calculations. J. Chem. Phys. 1991, 95, 8875-8894. [CrossRef]

68. Conors, K.A. Chemical Kinetics-The Study of Reaction Rate in Solution; Wiley: New York, NY, USA, 1990; p. 200.

69. Xu, F.; Yu, W.; Zhou, Q.; Gao, R.; Sun, X.; Zhang, Q.; Wang, W. Mechanism and direct kinetic study of the polychlorinated dibenzo-p-dioxin and dibenzofuran formations from the radical/radical cross-condensation of 2,4-dichlorophenoxy with 2-chlorophenoxy and 2,4,6-trichlorophenoxy. Environ. Sci. Technol. 2010, 45, 643-650. [CrossRef]

70. Frisch, M.J.; Trucks, G.W.; Schlegel, H.B.; Scuseria, G.E.; Robb, M.A.; Cheeseman, J.R.; Zakrzewski, V.G.; Montgomery, J.A.; Stratmann, R.E.; Burant, J.C.; et al. Gaussian 09, Revision A. 02; Gaussian, Inc.: Wallingford, CT, USA, 2015.

71. Zhao, Y.; Truhlar, D.G. Hybrid meta density functional theory methods for therochemistry, thermochemical kinetics, and noncovalent interactions: The MPW1B95 and MPWB1K models and comparative assessments for hydrogen bonding and van der Waals interactions. J. Phys. Chem. A 2004, 108, 6908-6918. [CrossRef]

72. Fukui, K. The path of chemical reactions-The IRC approach. Acc. Chem. Res. 1981, 14, 363-368. [CrossRef]

(C) 2019 by the authors. Licensee MDPI, Basel, Switzerland. This article is an open access article distributed under the terms and conditions of the Creative Commons Attribution (CC BY) license (http://creativecommons.org/licenses/by/4.0/). 